\title{
CRUZANDO A LINHA VERMELHA: QUESTÕES NÃO RESOLVIDAS NO DEBAIE SOBRE DIREITOS SEXUAIS
}

\author{
Sonia Corrêa \\ Grupo Internacional para Sexualidade e Política Social - Brasil
}

Resumo: No presente artigo busco apresentar as visões teóricas e políticas vigentes no campo que tem produzido um discurso sobre direitos sexuais, no sentido de chamar a atenção para as instabilidades e contradições que caracterizam as esferas nas quais vai sendo tecido um novo discurso "normativo" da sexualidade.

Palavras-chave: direitos sexuais, "lei”, políticas identitárias, sexualidade.

Abstract: The present paper aims to present theoretical and political views that play a role on the field that has produced a discourse about sexual rights in order to call attention to the instabilities and contradictions present in the construction of a new "normative" discourse about sexuality.

Keywords: identity politics, "law", sexuality, sexual rights.

Este artigo retoma, expande e tensiona idéias elaboradas em trabalhos anteriores acerca dos dilemas conceituais e prático-políticos que estão implícitos no empreendimento de conceituar e legitimar os direitos sexuais. A construção desses direitos não se dá num vácuo. Está necessariamente atravessada pelas concepções dominantes de gênero e sexualidade e outros determinantes tais como a capacidade normativa dos Estados nacionais e do sistema internacional de proteção dos direitos humanos, o impacto das forças de mercado, o fundamentalismo nas suas várias manifestações, e mais especialmente as desigualdades (de renda, raça e etnia; geracionais e decorrentes da existência de deficiências restritivas da capacidade física dos indivíduos). Aqui esses aspectos são, contudo, tratados de forma tangencial na medida em que o foco central do texto são as visões teóricas e políticas atuantes no campo que tem produzido um discurso sobre direitos sexuais. Da mesma forma, embora o debate sobre 
direitos sexuais tenha um escopo global, as reflexões aqui desenvolvidas buscam dialogar, sobretudo, como o contexto latino-americano do debate.

Um primeiro bloco trata das concepções teóricas que informam as conversações contemporâneas sobre sexualidade e direitos humanos e examina, brevemente, as visões e usos da lei e do direito. O segundo bloco analisa a cartografia de constituição dos sujeitos sexuais e de suas agendas políticas por referência ao contrato social moderno. O terceiro bloco explora questões relativas à lei penal. A última seção (re)visita o tema das identidades, a partir da pergunta “quem é o quem dos direitos sexuais?”. O resultado final é como um painel em mosaico que, inclusive, considero incompleto. No projeto original do artigo eu havia incluído um quinto tema: as divergências quanto ao prazer e a objetificação na sexualidade. Essa ambição inicial foi abandonada, pois exigia um investimento que não estava ao meu alcance no momento de elaboração do texto. Um outro tema que merecia ser mais plenamente desenvolvido diz respeito a situar o debate sobre direitos sexuais em relação a correntes relevantes do pensamento político contemporâneo, como é o caso das vertentes contemporâneas do liberalismo político (Jonh Ralws e Martha Nussbaum) e da corrente conhecida como democracia radical.

Esses limites só não são mais frustrantes por que este exercício é apenas uma estação num ciclo mais longo de reflexão. E, sobretudo, porque essas reflexões, embora parciais, são parte do esforço coletivo de produção deste volume. Em grande medida, é na relação dialogal com os demais trabalhos desta coletânea que as idéias aqui desenvolvidas ganham sentido e relevância.

\section{Enredos teóricos e visões políticas}

O que assistimos é um verdadeiro processo de luta; a vida como um objeto político foi de alguma maneira tomada pelo seu valor de face e voltada contra o sistema que a tentava controlar. Foi a vida mais que a lei que se tornou o objeto da luta política, mesmo quando esta luta política foi formulada através de afirmações relativas aos direitos. O “direito” à vida, ao corpo, à saúde, à felicidade, à satisfação das necessidades, a sobretudo o "direito" de redescobrir quem alguém é e o que pode ser... Este é o pano de fundo que nos ajuda a compreender o "sexo" como questão política. (Foucault apud Rabinov, 1984, p. 267, tradução minha).

No limiar na era moderna o sexo se converteu no pivô ao redor do qual toda a tecnologia da vida se desenvolve: o "sexo é um meio de acesso tanto à 
vida do corpo, quanto à vida da espécie; isto é ele oferece um meio de regulação tanto dos corpos individuais quanto do comportamento da população (o corpo político) com um todo” (Weeks, 1999, p. 51). Nessa passagem, a lei moderna inventou os "sujeitos sexuais" tais como os conhecemos. Independentemente da heterogeneidade dos sistemas jurídicos existentes, leis, códigos e normas continuam operando como sistemas de classificação, hierarquização e, na maioria dos casos, criminalização de identidades e práticas sexuais. É contra esse pano de fundo histórico que, ao longo da última década, assistimos à propagação de um rumor crescente sobre os direitos sexuais.

Um exemplo inequívoco é o parágrafo 96 da Plataforma de Ação de Pequim, que trata dos direitos humanos das mulheres em matérias relativas à sexualidade afirmando que nessa esfera as relações devem ser livres de coerção, discriminação e violência. A definição guarda vinculação estreita com o conceito de direitos reprodutivos legitimado, um ano antes, na Conferência Internacional de População e Desenvolvimento (Cairo, 1994) (Corrêa, 1999; Corrêa; Parker, 2004). Desde sua adoção essas duas definições têm inspirado interpretações e recomendações dos Comitês de Vigilância dos Direitos Humanos das Nações Unidas (Center for Reproductive Law and Practice; University of Toronto Program in Sexual and Reproductive Health Law, 2001), assim como iniciativas no sentido de sua "tradução" em leis e normas nacionais.

Deve-se dizer, porém, que, no contexto das Nações Unidas, a legitimação dos "direitos sexuais" das mulheres não foi acompanhada por avanços equivalentes no que se refere aos direitos da diversidade sexual (homossexuais, lésbicas, bissexuais, transexuais, transgêneros, trabalhadoras e trabalhadores do sexo). Em Pequim, embora se tenha aprovado o parágrafo 96, não foi possível incluir no parágrafo 227 - que trata das múltiplas formas de discriminação das mulheres uma menção explícita à orientação sexual. Em 2000, no processo de revisão de cinco anos da mesma conferência, uma vez mais a menção à orientação sexual foi sistematicamente recusada pelos países conservadores (Girard, 2000).

Em 2001, durante a Sessão Especial da Assembléia Geral sobre HIVAids, em junho, levantou-se objeção quanto à participação da representante da Comissão Internacional para os Direitos Humanos de Gays e Lésbicas e Transgêneros em uma mesa-redonda envolvendo governos e sociedade civil (Freitas, 2001). No mesmo ano, durante a preparação para Conferência Internacional contra o Racismo, Discriminação Racial e Formas de Intolerância, a acreditação da International Lesbian and Gay Association (Ilga) também foi questionada pela Conferência Islâmica Internacional. E, durante a própria con- 
ferência em Durban, uma vez mais, após debates acirrados, derrotou-se a proposta de inclusão da orientação sexual como base injustificável de discriminação e intolerância (Corrêa; Parker, 2004). Suzana Fried (2002), com razão, caracteriza essa resistência como "um persistente clima de homofobia institucional”.

A "homofobia" que se constata nos debates das Nações Unidas contrasta com processos em curso nas sociedades nacionais. Ao longo dos últimos quinze anos, a Comissão Européia de Direitos Humanos julgou mais de uma dezena de casos de "direitos sexuais" envolvendo situações de discriminação, casamento, adoção, troca de sexo e identidade de gênero e, inclusive, direito à privacidade de grupos sadomasoquistas. Os anos 1990 também seriam cenário de inúmeros debates e conquistas no que diz respeito aos direitos da diversidade sexual no mundo em desenvolvimento. No Equador, por exemplo, o princípio de não discriminação foi incorporado ao texto constitucional de 1991. Desde 1994, o princípio de não discriminação por orientação sexual foi adotado pela nova constituição sul-africana. ${ }^{1}$ Em vários países latino-americanos - Brasil, Argentina, México e Colômbia - estão em discussão no legislativo propostas de união civil ou sociedade de convivência entre pessoas do mesmo sexo. Na Índia, assim como em outros países asiáticos e africanos, anunciam-se iniciativas voltadas para reforma de códigos penais herdados do período colonial que incluem a "sodomia" como crime. Em contextos tão diversos quanto Brasil e a Nova Zelândia há mobilizações para garantir direitos laborais às trabalhadoras sexuais.

Se desde o século XIX - e com mais intensidade a partir dos anos 1960 as "leis do sexo" têm sido objeto sistemático de investigação, crítica e resistência; cabe perguntar em que medida esta nova proliferação de discursos que articulam sexo e lei se diferencia do que aconteceu no passado. Inúmeras distinções poderiam ser aqui pontuadas, mas para os objetivos deste artigo o aspecto mais relevante é que os sujeitos da política sexual ultrapassaram a linha vermelha, ou seja, seu investimento intelectual e político já não se restringe à arqueologia dos dispositivos da sexualidade e à desconstrução e reconstrução das identidades por elas definidas. O rumor dos direitos sexuais prospera, defi-

Nos debates de Pequim sobre o parágrafo 227, a delegação sul-africana foi uma das primeiras a tomar a palavra para afirmar que nenhuma forma de discriminação era aceitável.

Horizontes Antropológicos, Porto Alegre, ano 12, n. 26, p. 101-121, jul./dez. 2006 
nitivamente, no espaço discursivo e institucional de produção da própria "lei”. Esta não é uma travessia trivial.

O debate intelectual e político que fez da sexualidade um tema político na era contemporânea teve origem na "revolução sexual” dos anos 1960, mas ganhou densidade e legitimidade acadêmica a partir de sua vinculação com as teorias pós-modernas que situam a sexualidade no coração da formação cultural e política moderna. Essa inflexão intelectual - posteriormente denominada viragem lingüística - deu grande fôlego político aos movimentos societários que se mobilizam ao redor das questões da sexualidade. Sua crítica ao essencialismo extraiu o sexo da ordem natural das coisas para situá-lo em terrenos incomparavelmente mais plásticos: os discursos, instituições e práticas. ${ }^{2}$ As teorias pósmodernas também permitiram transportar a exclusão e o estigma - decorrentes dos discursos e normas modernas relativas à sexualidade - da esfera do patológico para o "exterior constitutivo” da política (Derrida apud Mouffe, 1999). Segundo Mouffe esse "lugar exterior" - onde a condição de constituição de toda e qualquer identidade é afirmação de uma diferença - é o que possibilita, nas condições contemporâneas, a reafirmação do político.

Entretanto, a viragem lingüística arrastava consigo uma zona de sombra: o marcado ceticismo dos teóricos pós-modernos em relação à idéia de transformação social e política, ou seja, em relação ao tema da emancipação. Essa "zona de sombra", que tem sido pouco debatida no campo em que se desenrola a conversação sobre os direitos sexuais, não pode ser eludida. Vários autores e autoras têm chamado atenção para o fato de que há diferenças significativas na posição dos autores pós-modernos ou pós-estruturais no que se refere ao ceticismo quanto à “emancipação” (Fraser, 1997; Moufffe, 1999). Contudo mesmo considerando a distância entre o que pensam, por um lado, Lyotard e Baudrillard, e, por outro, Derrida, Foucault (ou mesmo Judith Butler), de modo geral, a corrente intelectual pós-moderna forneceu aos atores da política sexual um poderoso instrumental analítico para compreender os mecanismos através dos quais instituições, leis, percepções e práticas sociais eram fontes de exclusão e estigma. Mas não oferece alternativas fáceis para programas de mudan-

\footnotetext{
Nesse sentido, a conversação contemporânea sobre o lugar e sentido da sexualidade na vida humana difere radicalmente daquelas que a precederam e que estavam fundamentalmente informadas pela concepção de sexo como instinto vital.
}

Horizontes Antropológicos, Porto Alegre, ano 12, n. 26, p. 101-121, jul./dez. 2006 
ça social, cultural e política na mendida em que expressa um marcado ceticismo em relação à concepção clássica do "sujeito político" - universal, racional, autoconstituído - bem como em relação à "lei” e ao "direito" como instrumentos potenciais de correção das injustiças. A ilustração mais vigorosa dessa posição é identificada nos escritos de Jacques Derrida:

A justiça do direito não é justiça. As leis exercem autoridade, mas não a justiça $\mathrm{O}$ direito funciona através da força e da violência. A justiça é uma aporia: uma experiência que não somos capazes de experimentar; o desejo do impossível; acaba sendo um chamado por justiça. O direito é calculo. A justiça é incalculável. ${ }^{3}$

Mas, como vimos, a despeito dessas recomendações teóricas, “os sujeitos políticos da sexualidade construída socialmente” estão intensamente engajados com os discursos e plataformas institucionais da lei e dos direitos humanos. Essa aproximação é inédita e muito estimulante. Mas não elimina automaticamente as tensões de fundo entre a epistemologia contemporânea da sexualidade - que enfatiza a fluidez, instabilidade das práticas e identidades sexuais - e os fundamentos da teoria e prática da lei e do direito, que se ancoram em premissas firmes de bom e mau, certo e errado.

Algumas idéias no sentido de explorar esse dilema foram desenvolvidas no artigo que escrevi com Richard Parker (Corrêa; Parker, 2004). Aí afirmamos que um primeiro passo no sentido de processar essas tensões é reconhecer a heterogeneidade presente no regime dos direitos humanos (Cervantes apud Rojas, 2001). Esse regime comporta uma corrente “moral” (absolutista) que, embora reconhecendo a existência de um debate sobre se os direitos humanos são moralmente necessários ou bons, afirma decisivamente que deve ser acordado universalmente que os direitos humanos são bons e necessários. Uma segunda vertente busca bases filosóficas e sociológicas para validar a premissa de universalidade dos direitos humanos. Ela comporta tanto posições essencialistas, que baseiam suas proposições "no que é essencial para a condição humana”, quanto posições que se interrogam sobre que condições sociais poderiam ser firmadas como argumentos universalizadores. Já a corrente pragmática argumenta que os direitos humanos são relevantes e universais na me-

Notas do seminário Lei e Direito em Derrida, Pontifícia Universidade Católica do Rio de Janeiro, agosto de 2002 .

Horizontes Antropológicos, Porto Alegre, ano 12, n. 26, p. 101-121, jul./dez. 2006 
dida em que sejam aceitos internacionalmente e posteriormente disseminados. Finalmente, existe também uma corrente "procedimental", menos conhecida, segundo a qual o que pode tornar os direitos humanos universais é o processo de sua construção, através de diálogos permanentes, democráticos, intersubjetivos e caracterizados pela reconhecimento das "diferenças" e pela reciprocidade.

Não parece excessivo afirmar que os atores e atrizes da "política sexual", em especial no contexto latino-americano, têm lançado mão dessas várias vertentes sem maiores reflexões quanto a suas implicações, riscos e limites. Se, por um lado, as perspectivas absolutistas e essencialistas podem não ser muito influentes entre aqueles e aquelas que hoje propõem uma pauta de direitos sexuais, elas são muito significativas, quando não hegemônicas, no campo mais amplo dos direitos humanos com o qual estamos, inevitavelmente, em interlocução constante. No próprio campo dos direitos sexuais é marcante a presença de iniciativas que se alinham à corrente "pragmática”. Esse é o caso, por exemplo, dos enfoques feministas que vêm investindo na definição de direitos sexuais como obrigações do Estado (deveres perfeitos). ${ }^{4}$ Por outro lado, os pressupostos da corrente procedimental são menos conhecidos e debatidos pelos os atores do campo.

Na medida em que já estamos, de fato, produzindo definições normativas, é preciso ter clareza quanto aos limites e possibilidades de cada um desses enfoques na relação como os pressupostos que têm informado nosso entendimento das sexualidades. Na minha avaliação, a corrente "moral”, assim como as vertentes essencialistas dos direitos humanos, estão epistemologicamente muito distantes - quando não em contradição aberta - com as concepções fluidas e instáveis das identidades e práticas sexuais. Entre outras razões porque, como lembra Miller (2001), essa instabilidade e fluidez não permitem definir fronteiras precisas entre o "bom” e o "mau”, definição essa que é um requisito das formulações absolutistas e essencialistas da lei e do direito.

Por outro lado, a vertente procedimental dos direitos humanos permite capturar e valorizar significados contextuais da sexualidade e está mais próxi-

4 Entre esses, são muito relevantes os esforços realizados por Rebecca Cook e seu grupo e pelo Cladem, que de fato está propondo a formulação de uma Convenção Interamericana sobre Direitos Sexuais e Reprodutivos. 
ma das propostas de esferas públicas plurais e situcionalidade dos debates morais que são muito relevantes para o desenvolvimento dos direitos sexuais e reprodutivos. ${ }^{5}$ Mas exatamente em razão dessa "abertura”, a corrente precedimental pode apresentar algumas limitações neste novo estágio em que já estamos engajados(as) na produção normativa. Por essa razão, nas reflexões desenvolvidas com Parker (Corrêa; Parker, 2004), sugerimos que poderia ser interessante explorar pontes entre a perspectiva procedimental e a corrente pragmática. Isso requer, por um lado, identificar os princípios gerais de direitos humanos que sejam suficientemente abertos para se constituírem em suportes de prerrogativas a serem aplicadas ao campo da sexualidade (pensada como construção social instável e maleável). Por outro, implica manter viva a premissa central da corrente procedimental, segundo a qual mais importante do que conteúdo dos acordos de direitos humanos são os processos através dos quais esses acordos são alcançados.

Nessa nova etapa - em que já ultrapassamos a linha vermelha - também é preciso reconhecer os “problemas não resolvidos” que derivam das visões e usos da lei e do direito que permeiam o campo político mais amplo em que esse debate se desenrola. No contexto latino-americano, por exemplo, o empreendimento dos direitos sexuais se desenvolve num "ambiente" fortemente marcado pela lei escrita (de tradição romana). Ou seja, em condições que diferem substancialmente daquelas que viram surgir os conceitos de direitos reprodutivos e sexuais que foi o ambiente da Common Law (de tradição anglo-saxônica), que não privilegia os códigos escritos, mas sim os princípios gerais do contrato social e os procedimentos de jurisprudência. Num artigo que escrevi com Rosalind Petchesky (Corrêa; Petchesky, 1994), analisamos os limites da tradição jurídica liberal (especialmente a anglo-saxônica) quando se tratava de conceber os direitos reprodutivos como direitos sociais, Concluímos então que a impregnação contratualista e individualista do “direito liberal” dificulta a formulação de medidas de correção substantiva de desigualdades, assim como a legitimação de prerrogativas coletivas e de direitos positivos.

Se transportamos esse exercício analítico para o contexto e a cultura jurídica latino-americana podemos identificar problemas adicionais. Embora o

As idéias de esfera pública plural e situcionalidade do debate moral podem ser identificadas no escritos de Plummer (2001) e Fraser (1997).

Horizontes Antropológicos, Porto Alegre, ano 12, n. 26, p. 101-121, jul./dez. 2006 
arcabouço de nossa tradição jurídica ofereça uma gama mais ampla de dispositivos de proteção, ou seja, direitos positivos, nos seus aspectos substantivos "nosso" contrato social não difere dos fundamentos liberais clássicos. Também aqui nos debatemos sistematicamente com o viés contratualista e individualista que, inclusive, acentuou-se por efeito das reformas econômicas liberais dos anos $1990 .{ }^{6}$ Por outro lado, nossa tradição é muito mais propensa a "sacralizar" normas e representações, um traço que tem rebatimentos sobre a cultura política no seu sentido mais amplo. Nas sociedades latinas, em geral, não pensamos a lei e o direito como uma espinha dorsal do contrato social que pode e deve se transformar à medida que se transformam os sujeitos que os produzem (e suas relações). Mas sim como um arcabouço quase mítico (platônico, poderíamos dizer) que “determina a realidade”. Além disso, na conjuntura atual, em face da crescente perda de capacidade indutiva e normativa dos Estados nacionais, assistimos ao surgimento e intensificação de demandas políticas no sentido de mais regulação e controle.

No contexto regional experimentamos hoje a consolidação de uma "cultura de direitos humanos" no interior da qual, inclusive, se ampliam as iniciativas de recurso aos instrumentos internacionais. Esse novo ambiente, por um lado, abre a possibilidade para ampliação de direitos em relação a esferas da vida que estavam excluídas do contrato social liberal clássico. Mas, por outro, aí também estão fortemente atuantes expectativas e demandas de maior controle normativo por parte dos Estados e das instâncias internacionais. O novo clima é favorável à construção dos direitos sexuais para além dos direitos de cidadania - exclusivamente referenciados aos Estados nacionais -, ou seja, concebidos como um processo de construção de direitos universais. Mas, ao mesmo tempo, continuamos nos movendo numa a cultura política que tende à sacralização da lei.

Esses paradoxos que determinam, inevitavelmente, as condições de realização de nossa reflexão e ação política devem ser examinados em relação às diferentes escolhas que podem ser feitas em relação às várias vertentes dos direitos humanos. Uma perspectiva de direitos sexuais que concebe a sexualidade como fato natural, privilegia a norma escrita e pensa o direito como

6 O viés contratualista de nossa tradição é particularmente acentuado no direito de família. 
parâmetro de regulação robusta das práticas sociais e sexuais (enforcement) irá, possivelmente, optar pelas correntes moral ou essencialista dos direitos humanos. Já as posições que privilegiam a concepção de sexualidades construídas e instáveis e visualizam a justiça como idéia reguladora (o objetivo inalcançável de Derrida) irão optar pela perspectiva procedimental, ou talvez buscar sínteses provisórias entre essa corrente e a visão pragmática dos direitos humanos.

Estas reflexões não têm a pretensão de esgotar a enorme complexidade das questões que podem se identificadas na charneira entre a teoria e ação política dos direitos sexuais. Elas apenas visam chamar atenção para as instabilidades e contradições que caracterizam os campos nos quais vai sendo tecido um novo discurso "normativo" da sexualidade. O desenvolvimento pleno de uma perspectiva aberta e plausível dos direitos sexuais não pode prescindir do processamento das disjunções e convergências que aqui foram delineadas.

\section{Dentro e fora do contrato social}

Rompendo abertamente com a tradição ocidental que "aceitava" o homoerotismo, a modernidade transformou o "homem que faz sexo com homens" em uma nova criatura, num segundo "outro" problemático. A mulher, com sua florescente diferença, seria situada em oposição complementar ao homem. O invertido - como a terminologia indica precisamente - tornou-se o exato contrário do homem. Espelhando-se nesses “outros íntimos”, o homem do Iluminismo podia definir e reafirmar sua própria natureza (superior). (Corrêa, 2000, p. 180).

A invenção dos direitos sexuais guarda um vínculo estreito com a longa trajetória de reconstrução de leis nacionais e do próprio paradigma dos direitos humanos a partir da perspectiva das mulheres. Mas quando se considera a multiplicidade de sujeitos que hoje demandam prerrogativas no campo da sexualidade, é preciso dizer que sua aproximação com a lei e o direito foi mais tardia, e tem sido construída a partir de parâmetros que nem sempre coincidem com a perspectiva feminista. Em reflexões anteriores, examinei as tensões de natureza política entre os atores do campo de direitos sexuais (Corrêa; Parker, 2004; Rojas, 2001). Aqui se trata de analisar essas disjunções tendo como referência o ciclo longo de constituição das identidades sexuais na sua relação com a lei e o direito. Minha hipótese de trabalho é de que essa "dissonância" deriva fundamentalmente da diferença (não pequena) entre posição ocupada, de um 
lado, pelas mulheres e, de outro, pelas sexualidades dissidentes no arcabouço jurídico do contrato social moderno.

Na passagem para a modernidade, quando o "sexo" se converteu em pivô de articulação entre o mundo da vida e administração do corpo político, as mulheres não foram excluídas do contrato social, mas sim posicionadas desigualmente e confinadas de jure ou de facto à esfera privada. Como bem analisa Laqueur (1990), essa desigualdade de posição foi justificada pelos filósofos do século XVIII como necessária para “domesticar” impregnação sexual do corpo feminino, que também determinava a diferença radical das mulheres em relação aos homens. Embora posicionadas desigualmente em razão de "sua sexualidade" as mulheres ocupavam (e ocupam) uma função nuclear no contrato social: a "reprodução" (patrimônio, herança, filiação, manutenção da vida cotidiana, a face submersa da economia). Por efeito dessa centralidade as leis das "mulheres" foram (e continuam) predominantemente inscritas nos códigos civis. Em contraste, os demais “sujeitos sexuais” têm sido, sistematicamente, pensados como objetos dos códigos penais. Dito de outro modo, enquanto as "mulheres” se situavam (ainda se situam) “desigualmente” no interior do contrato, os outros sujeitos potenciais dos direitos sexuais estavam (e estão), de fato, posicionados na sua margem (excluídos). Essa é a mesma lógica que faz do adultério, da prostituição feminina e do aborto matérias penais. ${ }^{7}$

Essa diferença "constitutiva" está longe de ter sido eliminada das normas jurídicas, continua atuante no imaginário social e, sobretudo, marcou de maneira diferenciada as pautas dos atores e atrizes da política sexual. Por exemplo, por efeito da "interioridade" das mulheres, a posição feminista tem refletido historicamente "maior confiança” na lei e tem menos hesitações quanto a fazer reivindicações de direito positivo (demandas de proteção). Já os demais “sujeitos sexuais” - homossexuais, trabalhadoras do sexo, transexuais, etc. - manifestam grande desconfiança quanto ao potencial de violência da lei, privilegiam

\footnotetext{
7 O debate inconcluso sobre o lugar da prostituição feminina na lei é ilustrativo dessa disjunção, ou, se quisermos, ambigüidade. A controvérsia desde sempre gira ao redor da questão de se as mulheres que se prostituem devem ser elas mesmas criminalizadas ou se a punição deve ficar restrita ao corruptor ou àqueles que auferem benefícios da prostituição. $\mathrm{O}$ outro debate recorrente diz respeito à "funcionalidade social da prostituição", ou seja, como mal necessário que garante a sustentabilidade dos contratos conjugais. Este tipo de dúvida ou dilema não é identificado, contudo, nos discursos sobre a homossexualidade masculina, sistematicamente concebida e tratada como desvio da norma.
}

Horizontes Antropológicos, Porto Alegre, ano 12, n. 26, p. 101-121, jul./dez. 2006 
a agenda dos direitos negativos (não discriminação e tratamento igual perante a lei) e são, com freqüência, relutantes quanto a medidas de proteção estatal.

Da mesma forma, o apelo sistemático das feministas no sentido de que as fronteiras entre público e privado sejam reconfiguradas deve ser examinado à luz desta dicotomia (dentro e fora do contrato social). Nada ilustra melhor o imaginário político da "interioridade constitutiva das mulheres” do que as proposições feministas, no sentido de reconstrução da cidadania a partir das características do "cuidado" que definem função das mulheres na esfera privada (Pateman, 1988). Mas há, como se sabe, outras correntes que pensam a redefinição dessas fronteiras em termos de equalização entre esfera privada e pública e "abertura” da esfera privada para permitir medidas de proteção contra a desigualdade e o abuso que aí vicejam, quando não se originam. A “interioridade” das mulheres também está associada à fusão entre sexo e gênero, que é muito freqüente na teorização feminista. Várias autoras e autores identificam nesta fusão um apagamento da sexualidade como esfera diferenciada de discursos e práticas (Corrêa, 1999; Parker, 1991; Rubin, 1984).

Já os demais sujeitos sexuais têm na esfera diferenciada da sexualidade o lugar constitutivo de suas identidades e demandas políticas. Sua problematização da divisão entre público e privado não se faz na mesma direção das feministas. Expressam grande cautela, quando não franca resistência, frente a propostas que visam abrir a esfera privada para intervenção do Estado. E, sobretudo, em anos mais recentes o direito a união civil - ou seja, à afetividade e privacidade - tem sido um dos temas mais importantes das lutas legais em que gays e lésbicas estão envolvidos, e contém, implicitamente, um apelo ao respeito pela privacidade e intimidade. Deve-se dizer, inclusive que um dos traços mais importantes das lutas que se desenvolvem na região para assegurar a união civil ou sociedade de convivência entre pessoas do mesmo sexo é exatamente seu significado em termos de deslocar a questão homossexual da lei penal para um dos núcleos da lei civil, que é o direito de família.

No conjunto, essas muitas disjunções sugerem que não é possível fazer uma transposição automática entre a "reforma das leis do gênero" e a construção de direitos no campo da sexualidade. Não deveríamos nos aproximar dos direitos sexuais como se fossem uma simples extensão ou aprofundamento de prerrogativas relativas à correção da desigualdade entre os gêneros no campo da sexualidade. $\mathrm{O}$ investimento no sentido de firmar premissas e procedimentos de justiça erótica requer "inventar regras, leis, a cada vez, sem critérios prévios o que é sempre uma invenção violenta, um "acontecimento” (Derrida 
apud Perrone-Moysés, 2001, p. 12-13). Essa invenção implica, entre outras coisas, enfrentar o tema da lei penal.

\section{0 direito de punir}

No campo em que são construídos os direitos sexuais, há um único consenso robusto quanto à aplicação da lei penal: a punibilidade do estupro e sua qualificação como crime contra a pessoa (ou seja, uma infração grave dos direitos humanos). Nos anos 1990, uma das conquistas mais significativas do feminismo global foram as definições de Viena, e mais especialmente do Tribunal Penal Internacional, que definem o estupro sistemático em situação de conflito como crime contra a humanidade.

Contudo, quando examinado a partir de uma lente plural dos direitos sexuais, mesmo esse consenso é parcial, pois continua, fundamentalmente, referenciado às mulheres. No desenvolvimento do debate contemporâneo sobre estupro e direitos humanos, a violação de meninos, homens, travestis, transgêneros e demais dissidentes sexuais têm sido francamente marginal. Sem dúvida, os episódios recentes de pedofilia da Igreja Católica fizeram eclodir na cena pública o escândalo quanto ao sexo não consentido entre homens e meninos. Entretanto, não estão em pauta os abusos da integridade sexual de "outros” que não as mulheres. São, por exemplo, muito escassas as pesquisas acerca do estupro sistemático nos sistemas prisionais masculinos. ${ }^{8}$

Há também um razoável consenso quanto a excluir das leis criminais a sodomia (nos casos em que a prática homossexual masculina é assim caracterizada), o adultério e o aborto. Mas quando se trata dos demais objetos "sexuais” das leis penais - prostituição e tráfico, pornografia e "uso do corpo da mulher na mídia”, para mencionar apenas os temas mais debatidos - o que tem prevalecido são tensões, controvérsias e cisões. Isso se dá tanto no interior do campo feminista quanto entre feministas e demais atores da política sexual. Nos Estados Unidos, por exemplo, desde os anos 1980, essas tensões têm sido muito acirradas, e delas decorrem a oposição radical entre autoras que são referência para o debate regional sobre sexualidade e direitos humanos das

8 Uma exceção que confirma a regra é o estudo de Jacobo Sikora Schifter (1988) em Amor de Machos. 
mulheres, como é caso de Gayle Rubin e Catherine Mac Kinnon. Esse debate está longe de ter-se esgotado. ${ }^{9} \mathrm{E}$, muito embora as propostas de criminalização de determinadas práticas sexuais sejam mais freqüentes entre as feministas, é significativo constatar que em anos recentes grupos homossexuais também têm feito apelos no sentido de aplicação da lei penal. ${ }^{10}$

Não é possível examinar em profundidade as visões, posições e argumentos que estão em jogo nessas muitas controvérsias. Possivelmente, a concepção de direito como instrumento de punição que impregna nossa cultura explica, parcialmente, a ausência de um debate sistemático, entre os atores do campo, quanto aos significados, limites e riscos da lei penal. Entretanto, no coração das controvérsias podem ser identificadas questões mais complexas, como é o caso das divergências quanto aos significados do prazer, da violência e da objetificação na esfera da sexualidade. Aqui vou me limitar a trazer algumas reflexões críticas a respeito da associação entre lei penal e sexualidade. ${ }^{11}$

Na seção anterior já foi suficientemente enfatizada a forte correlação entre sexo e crime no contrato social moderno. Miller (2001), por sua vez, sugere que é preciso ter muita cautela acerca dos efeitos não antecipados das reformas da lei penal quando se trata de situações relativas ao sexo. Usa como ilustração o caso da reformas das leis estatutárias sobre estupro nos Estados Unidos dos anos 1920, pois a revisão histórica cuidadosa dessas medidas revelou que "a nova lei era mais invocada pelas famílias quando o amante masculino das filhas pertencia à classe, raça ou etnia ‘errada'” (Miller, 2001, tradução minha). A autora se pergunta se um efeito equivalente não poderá ocorrer, nos dias atuais, nos vários contextos em que as feministas reivindicam a criminalização de homens que abusam de mulheres e meninas, ou seja, que o apelo à

9 O último livro de Martha Nussbaum (1999), Sex and Social Justice, dedica três artigos ao tema, sendo que em dois a filósofa desenvolve uma argumentação direta com Catherine Mac Kinnon e Andréa Dworkin, que são as vozes mais conhecidas de condenação da pornografia e prostituição.

${ }^{10}$ Grupos gays brasileiros, por exemplo, têm encaminhando propostas no sentido de criminalizar práticas de discriminação e homofobia, iniciativas que se inspiram no tratamento do racismo como crime inafiançável, adotado pela lei brasileira nos anos 1970.

${ }^{11} \mathrm{O}$ projeto original deste artigo incluía uma sessão voltada para examinar esta dimensão do debate. Contudo, no desenvolvimento do texto revelou-se que esta é uma proposição por demais ambiciosa e que extrapolava em muito minhas possibilidades de reflexão no tempo disponível. Também concluí que a inclusão de reflexões preliminares e parciais sobre a questão da objetificação poderia comprometer a consistência não só do artigo como também dos meus próprios argumentos. De qualquer modo, o desafio de enfrentar a questão continua na minha pauta de reflexão para o futuro próximo.

Horizontes Antropológicos, Porto Alegre, ano 12, n. 26, p. 101-121, jul./dez. 2006 
criminalização seja convertido em justificação para caucionar outras formas de exclusão ou mesmo mobilizar justiça pelas próprias mãos (punição extrajudicial). $\mathrm{O}$ fato de que, no contexto latino-americano, com freqüência, os estupradores sejam linchados ou assassinados quando chegam à prisão sugere que esta hipótese não é exatamente absurda.

A jurista brasileira Maria Lúcia Karam (2002) problematiza de maneira ainda mais contundente o uso da lei penal. Segundo a autora, a definição de “crimes sexuais” não deriva dos princípios de justiça ou de proteção dos indivíduos, mas sim de uma lógica que visa a obtenção de disciplina moral e social:

Não pode, pois, a lei penal ser utilizada para imposição de pautas morais de comportamento, em um campo que está reservado às convicções íntimas e à consciência individual. Neste campo, o Estado não pode intervir, não se podendo confundir Direito e Moral, como tampouco crime e pecado. Quando se erige uma moral pública sexual, qualquer que seja esta, à categoria de bem jurídico, o que se acaba por estabelecer é a imposição de uma concepção moral dominante sobre a sexualidade, que, embora possa até ser compartilhada pela maioria dos membros da sociedade, pode não ser aceita por indivíduos ou grupos sociais, cujo direito à diferença há de ser garantido, sempre que não atingidos direitos alheios. (Karam, 2002).

Se examinarmos as condições reais de implementação das leis penais em relação à sexualidade não é difícil constatar que Karam está correta. Em nossas sociedades a criminalização da prostituição, da homossexualidade (ou mesmo do aborto) não visa aprisionar todas as pessoas que cometem esses "crimes”, mas sim criar e sustentar uma atmosfera "moral” de condenação. Para que esse objetivo seja atingido é necessário implementar a lei episodicamente, pois só assim as sociedades (e pessoas) "se lembram” de que a norma existe. Em geral a aplicação exemplar da lei penal em relação a crimes sexuais atinge aqueles e aquelas que estão sujeitos a outras formas de desigualdade e estigma: prostitutas de rua, michês, travestis, mulheres pobres (no caso do aborto).

Para superar essa cultura autoritária que é persistentemente alimentada pela idéia de “crime sexual”, Karam propõe a diferenciação, conceitual e política, entre moral e direito. Ela também enfatiza que, nos debates políticos e nos procedimentos de operação da justiça, é preciso sempre garantir a primazia dos princípios constitucionais de dignidade, liberdade e privacidade sobre a lei penal, ou seja, estabelecer limites constitucionais para o "direito de punir”. Essas premissas, que foram pensadas originalmente por referência ao aparato jurídi- 
co dos Estados nacionais, podem e devem ser estendidas à construção dos direitos sexuais no plano dos instrumentos internacionais de direitos humanos, já que esses instrumentos estão fundamentados nos mesmo princípios gerais de dignidade, liberdade, privacidade, segurança pessoal. Entretanto, para que esse giro possa ocorrer, é preciso que as diferenças no plano da visão e uso da lei sejam nomeadas e processadas pelos atores plurais da política sexual.

\section{Quem é o "quem"?}

O primeiro consenso "normativo" global dos direitos sexuais ocorreu em Pequim pelas mãos das feministas (e de alguns setores lésbicos), ou seja, ficaram dele "excluídos" os demais atores políticos envolvidos na conversação. O conteúdo do parágrafo 96 é não só específico dos direitos humanos das mulheres na esfera da sexualidade como comporta dois blocos cujos conteúdos são radicalmente diversos. A primeira parte do parágrafo é “aberta”, afirmando os "direitos sexuais" das mulheres como ausência de e proteção contra coerção, discriminação e violência, uma formulação que poderia facilmente alterada no sentido de definir os direitos de todas pessoas na esfera da sexualidade. Entretanto, a segunda parte do parágrafo - que resultou de uma exigência dos países islâmicos - tem franca conotação heterossexual. Não sem razão, as condições em que se produziu esse primeiro consenso global sobre os direitos sexuais, assim como seu resultado, têm sido objeto de críticas severas por parte de intelectuais e ativistas do campo homossexual.

A meu ver, a lição mais significativa da negociação de Pequim é a de que os consensos "normativos", mesmo os mais progressistas, são contingentes e excludentes. Nas condições políticas contemporâneas a produção de consensos institucionais desencadeia novos processos de disputa de participação e significado. Isso implica que para responder a pergunta "quem é o quem dos direitos sexuais?” é preciso assegurar a pluralidade no espaço de debate e processar as inevitáveis tensões que dela decorrem. ${ }^{12}$

\footnotetext{
${ }^{12}$ Nas atuais condições políticas - em face do ataque virulento das forças do conservadorismo moral contra as definições do Cairo e de Pequim - nos vemos "forçadas" a defender, com unhas e dentes, os consensos legitimados, ainda que eles sejam contigentes e parciais. Em que pesem os problemas da conjuntura imediata é fundamental manter abertura intelectual em relação ao que podem vir a ser os direitos humanos na esfera da sexualidade, assim como no que diz respeito a quem é o sujeito desses direitos.
} 
Entretanto, essa pergunta (quem é o quem?) também nos instiga a revisitar o debate teórico sobre identidade, representação política e norma jurídica. Um exercício possível nessa direção é o de explorar a questão a partir da perspectiva de Judith Butler (1990). Butler considera que não somente o gênero, mas o próprio sexo é resultado de uma modelação cultural que inclui a norma jurídica (quem é meu nome?). Sobretudo, problematiza a própria categoria mulher (homem) como fonte de legitimidade representacional frente aos regimes jurídicos: "Na verdade a questão da mulher como sujeito do feminismo levanta a possibilidade que pode não haver um sujeito frente à lei, esperando para ser representado na ou pela lei” (Butler, 1990, p. 3, tradução minha). ${ }^{13}$

O projeto de Butler é claramente cético quanto às possibilidades de reforma dos regimes jurídicos. Mas sua concepção de instabilidade e falta de substância ontológica dos sujeitos sexuais é instigante para pensar quem é o “quem” dos direitos sexuais. Seu ponto de partida (e de chegada) são as práticas paradoxais de sexo/gênero que possibilitam - tanto nas experiências dos sujeitos quanto nos acordos lingüisticos - uma proliferação que vai muito além do modelo dos dois sexos: as drag queens, queers, transgêneros. A partir desse lugar Butler irá conceber sexo-gênero como performance, como desempenho individual e relacional que é parte de um jogo mais amplo de roteiros culturais (e sociais).

Na conversa sobre os direitos sexuais as performances de sexo-gênero devem ainda ser examinadas em termos da articulação com outras identidades (ou seja, as categorias lingüísticas, subjetivas e jurídicas que não derivam do trinômio corpo-sexo-gênero). Mouffe e Laclau (1985) já há algum tempo haviam formulado uma grade analítica para pensar a democracia a partir do reconhecimento das múltiplas posições subjetivas e sociais dos sujeitos políticos. Miller (2001) caminha na mesma direção, chamando atenção para sobreposição ou disjunção entre as identidades sexuais e as outras identidades - raça, classe, etnia, profissão, situação marital, etc. - que também estão inscritas nas representações sociais, experiências subjetivas e regimes jurídicos. Explora, especialmente, a "sexualização” dessas outras identidades, ou seja, sua classificação

\footnotetext{
${ }^{13}$ No texto de Butler (1990, p. 3, tradução minha) essa afirmação se completa da seguinte maneira: “A assunção dominante de uma integridade ontológica do sujeito que existe antes da lei pode ser interpretada como traço contemporâneo da hipótese do estado de natureza, que é esta fábula fundacional constitutiva das estruturas jurídicas do liberalismo clássico.”
} 
e hierarquização a partir de categorias sexuais. Miller lembra, inclusive, que o discurso nazista também lançou mão da descrição sexual, pois os judeus eram descritos como efeminados em contraposição à virilidade alemã. No nosso contexto cultural a ilustração mais pertinente e conhecida é, possivelmente, a persistente sexualização/erotização de homens e mulheres negras, que terá denotações negativas ou positivas a depender do "contexto" em que se situem as práticas e se produzam os discursos valorativos.

A distância crítica que estas autoras guardam em relação à genealogia dos sujeitos na sua relação com a sexualidade e os regimes jurídicos é um sinal de alerta permanente (e necessário) em relação à naturalização do contrato social e de suas lógicas de inclusão e exclusão. Constitui, a meu ver, um instrumento poderoso para prevenir a "sacralização" da lei - inclusive dos instrumentos de direitos humanos, e a "cristalização" das identidades sexuais e sociais. Sobretudo nos inspira a interrogações de fundo. A sedimentação gradativa de princípios de justiça erótica implica fixar ou, ao contrário, diluir a polimorfia dos sujeitos sexuais? Concebemos os direitos sexuais como invocação das prerrogativas específicas de cada uma dessas categorias "performáticas”? Nosso projeto supõe fazer de cada uma das definições das sexualidades hierarquizadas, tal como delineadas por Gayle Rubin (1984), suporte de demandas jurídicas negativas e positivas? Ou, ao contrário, trata-se de reconhecer o caráter fluido, instável, mutável das “identidades sexuais” e buscar definições as mais abertas possíveis para delimitar suas prerrogativas enquanto sujeitos que experimentam a sexualidade?

Se optarmos por esta última alternativa, uma trilha a ser percorrida é, talvez, o recurso ao conceito de "quem” (quid) elaborado por Hannah Arendt (1973) para descrever aparição diferencial dos sujeitos na esfera pública. Na formulação da autora, o “quem” é uma referência inegociável, pois assegura o reconhecimento da pluralidade no mundo da vida e alimenta a alteridade como fundamento da política. À luz dessa perspectiva, a proliferação de vozes e sujeitos sexuais é mais que bem-vinda como fonte de enriquecimento da política no seu sentido amplo, e do diálogo sobre direitos sexuais de forma mais específica. Entretanto, para Arendt (1973), a alteridade do “quem” - embora construída a partir da experiência diferenciada dos sujeitos - não se funda em corpos e práticas como suportes ontológicos do "ser" ou das prerrogativas jurídicas (isto é o que fazem as "leis do sexo”). A aparição diferenciada do "quem” se conjuga com o reconhecimento de uma humanidade comum que é subjacente e ao mesmo tempo mediada pelas “diferenças". 
A concepção arendtiana implica, portanto, uma dialética sutil entre visibilidade política das “diferenças” e apagamento filosófico dos corpos e práticas. ${ }^{14}$ Essa visão proporciona uma nova chave de leitura dos dilemas que enfrentamos no processamento da equação difícil em que se articulam sexualidades, identidades, política, discursos e regimes jurídicos. A dialética arendtiana pode, talvez, favorecer um projeto de construção dos direitos sexuais que não silencia a pluralidade e nem tampouco seja uma mera (re)inscrição de práticas e corpos sexuais no regime discursivo e jurídico das leis e dos direitos humanos. ${ }^{15}$

\section{Referências}

ARENDT, Hanah. The human condition. 8. ed. Chicago: Chicago University Press, 1973.

BENHABIB, S. The reluctant modernism of Hannah Arendt. Thousand Oaks: Sage, 1996.

BUTLER, J. Gender trouble: feminism and the subversion of identity. New York: Roultlege, 1990.

CENTER FOR REPRODUCTIVE LAW AND PRACTICE; UNIVERSITY OF TORONTO PROGRAM IN SEXUAL AND REPRODUCTIVE HEALTH LAW. The application of human rights to reproductive and sexual health: an analysis of the work of international human rights treaty bodies. New York, 2001. Mimeografado.

\footnotetext{
${ }^{14}$ Este apagamento do corpo e da experiência subjetiva foi analisado por Seyla Behanib (1996) como "pudor", como um traço do que ele denomina "o modernismo relutante de Hannah Arent".

${ }^{15}$ Este caminho nos aproxima das correntes conhecidas como pós-identitárias - que apontam para o fim do feminismo, da homossexualidade, etc. Sei bem que no espaço da ação política, as propostas no sentido de uma política pós-identitária suscitam fortes reações pois a coreografia do nosso campo de debate ainda é predominantemente determinada pelas identidades sexuais. Isto indica que não é possível saltar num passe de mágica sobre as condições reais de realização da política da sexualidade. Mas isto não deveria nos impedir da continuar explorando possibilidades que permitam superar as "perversões" da política de identidades já que elas constituem um obstáculo importante no caminho de construção dos direitos sexuais.
}

Horizontes Antropológicos, Porto Alegre, ano 12, n. 26, p. 101-121, jul./dez. 2006 
CORRÊA, Sonia. Saúde reprodutiva, gênero e sexualidade: legitimação e novas interrogações. In: COSTA, Sarah; GIFFIN, Karen (Org.). Questões de saúde reprodutiva. Rio de Janeiro: Editora Fiocruz, 1999. p. 39-50.

CORRÊA, Sonia. Gênero e sexualidade: diferença, direitos e tolerância: significados, vertentes teóricas e implicações não antecipadas de nossos percursos. In: CÁCERES Carlos et al. (Org.). A saúde como direito cidadão. Lima: Universidade Peruana Cayetano Heredia, 2000. p. 175-184.

CORRÊA, S.; PARKER, R. Sexuality, human rights and demographic thinking: connections and disjunctions in a changing world. Sexuality Research and Social Policy, v. 1, n. 1, p. 15-38, 2004.

CORRÊA, S.; PETCHESKY, R. Sexual and reproductive rights in the feminist perspective. In: SEN; GERMAIN; CHEN (Org.). Population policies reconsidered: health, empowerment, and rights. Cambridge: Harvard School of Public Health, 1994. p. 102-123.

FRASER, N. Justice interruptus. New York: Routledge, 1997.

FREITAS, A. Linking throuh closed doors.Trade, AIDS, Public Health and Human Rights: Dawn Informs Special Supplement, p. 9-11, August 2001.

FRIED, Suzana. [Intervenção no painel de debates sobre Pequim+10]. IX Fórum Internacional AWID, Guadalajara, México, set. 2002.

KARAM, M. L. A interpretação da lei penal e crimes sexuais. Palestra proferida no Seminário "Conversando Direito sobre Homossexualidade”, promovido pelo Grupo Arco-Íris, Rio de Janeiro, ago. 2002.

LAQUEUR, T. Making sex: body and gender from the Greeks to Freud. London: Harvard University Press, 1990

MILLER, A. Sexual rights, conceptual advances: tensions in the debate. 2001. Texto apresentado no seminário Sexualidad, Reproducción y Derechos Humanos, organizado pelo Conselho Latino-Americano pelo Direitos das Mulheres, Lima, novembro de 2001. Mimeografado.

MOUFFE, C. El retorno de lo político: comunidad, ciudadania, demoracia radical. México: Paidos, 1999. 
MOUFFE, C.; LACLAU, E. Hegemony and socialist strategy: towards a radical democratic politics. London: Verso, 1985.

NUSSBAUM. M. Sex and social justice. New York: Oxford University Press, 1999.

PARKER, R. G. Bodies, pleasures and passions: sexual culture in contemporary Brazil. Boston: Beacon Press, 1991.

PATEMAN, C. The sexual contract. Palo Alto: Stanford University Press, 1988.

PERRONE-MOYSÉS, L. Derrida no Rio. Folha de S. Paulo, 8 jul. 2001. Caderno Mais, p. 12-13.

PLUMMER, K. Sexualities in a runaway world: utopian and dystopian challenges. Paper apresentado na conferência Sexuality and Social Change, Associação Brasileira Interdisciplinar de Aids (Abia), Rio de Janeiro, 2001.

RABINOV, Paul (Org.). Foucault reader. New York: Pantheon Books, 1984.

ROJAS, Lorena. 2001. El debate sobre los derechos sexuales en México. Ciudad de México: Colégio de México, 2001. (Programa de Salud Reproductiva y Sociedad).

RUBIN, G. Thinking sex: notes for a radical theory of the politics of sexuality. In: VANCE, C. S. (Ed.). Pleasure and danger: exploring female sexualityance. Boston: Routledge and Kegan Paul, 1984. p. 267-319.

SIKORA SCHIFTER, J. Amor de machos. San José: Ilpes, 1988.

WEEKS, J. O corpo e a sexualidade. In: LOURO, Guacira Lopes (Org.). O corpo educado. Belo Horizonte: Autêntica, 1999. p. 35-82. 